\begin{tabular}{|c|l|}
\hline Title & U pward Infiltration into Porous Media as A ffected by Wettability and A nionic Surfactants \\
\hline Author(s) & Ishiguro, Munehide; Fujii, Tomokazu \\
\hline Citation & $\begin{array}{l}\text { Soil Science Society of A merica Journal, 72(3), 741-749 } \\
\text { https://doi.org/10.2136/sssaj2006.0367 }\end{array}$ \\
\hline Issue Date & 2008 \\
\hline Doc URL & http://hdl.handle.net/2115/68463 \\
\hline Rights & Copyright $\odot$ 2008. Soil Science Society. Soil Science Society of A merica \\
\hline Type & article (author version) \\
\hline File Information & SSSA Jpaper.pdf \\
\hline
\end{tabular}

Instructions for use 


\section{Upward Infiltration into Porous Media as Affected by Wettability and Anionic Surfactants}

\section{Munehide Ishiguro*, and Tomokazu Fujii}

Munehide Ishiguro*, Graduate School of Environmental Science, Okayama University, 3-1-1 Okayama, 700-8530 Japan

Tomokazu Fujii, Toray Industries, Inc., 2-1-1 Nihonbashi-Muromachi, Chuo-ku, Tokyo, 103-8666 Japan

*Corresponding author (ishi@cc.okayama-u.ac.jp; TEL/FAX 81-86-251-8875)

\section{ACKNOWLEDGMENTS}

We thank Mitsui Chemicals for supplying polyethylene particles (Hi-zex MILLION 340 M). This research was supported by a Grant-in-Aid for Scientific Research (KAKENHI;14560198) from Japan Society for the Promotion of Science. 


\section{ABSTRACT}

The influence of surfactants on water infiltration has not been thoroughly evaluated due to the 5 diversity and complexity of soils. The purpose of this study was to propose an equation for upward 6 infiltration by capillary action under gravity based on Darcy's law and to use the equation to determine the 7 effect of an anionic surfactant on infiltration in porous materials. We showed that this new equation is 8 equivalent to the Washburn equation, which has been widely used for measuring contact angles in 9 powdered solids. We examined upward infiltration of sodium dodecyl sulfate (SDS; from 0 to 700 mol $10 \mathrm{~m}^{-3}$ ) into dry materials. The new equation evaluated infiltration well. In glass beads and sand, which are 11 both hydrophilic, the infiltration rate decreased as the SDS concentration increased due to a decrease in 12 solution surface tension (from 72 to $38 \mathrm{mN} \mathrm{m}^{-1}$ ). Major changes in the contact angle were not observed. In 13 polyethylene particles and peat moss, which are hydrophobic organic materials, the infiltration rate 14 increased as the SDS concentration increased, mainly because of the decrease in the contact angle (from $15>125^{\circ}$ to $69^{\circ}$ for polyethylene, from $102^{\circ}$ to $43^{\circ}$ for peat moss). In leaf mold, the infiltration rate decreased 16 as the SDS concentration increased due to the decrease in the saturated hydraulic conductivity caused by 17 swelling. SDS adsorption probably resulted in swelling. Surface tension, contact angle, and adsorption, 18 which were all affected by SDS concentration, caused the different infiltration rates.

Abbreviations: SDS, sodium dodecyl sulfate; CMC, critical micelle concentration. 
Surfactants are used in detergents, shampoos, and chemical fertilizers as an anti-caking agent, in agricultural chemicals as an emulsifying agent, and for other uses. Surfactants are also used for remediating contaminated soil, enhancing oil recovery (West and Harwell, 1992), and ameliorating soil-water repellency (Cisar et al., 2000; Kostka, 2000). Enormous quantities have been used, and much waste material has been discharged into the environment (Lewis, 1991). Because surfactants degenerate cells (Sakashita, 1979), they strongly affect living organisms and ecosystems (Lewis, 1991). Their overall influence on the soil environment is not fully understood.

Solid surface characteristics are changed when surfactants are adsorbed on solid surfaces (Koopal et al., 1999). Surfactants also decrease water surface tension. Therefore, surfactants influence water and solute movement in soils. The influence of surfactant concentration on unsaturated flow caused by the depression of surface tension has been reported (Karkare and Fort, 1994; Smith and Gillham, 1994, 1999; Henry et al., 1999; Henry and Smith, 2002). Surfactant application increases the infiltration rate into hydrophobic soils consisting of sands coated with organic compounds (Pelishek et al., 1962; Feng et al., 2002). The application of nonionic surfactant either before or with irrigation increases the dispersion of a hydrophobic sandy loam (Mustafa and Letey, 1969), and this dispersion decreases flow rates in the soil (Miller et al., 1975). Soil hydraulic conductivity decreases when sodium dodecyl sulfate (SDS) is applied due to precipitation of the divalent electrolyte dodecylsulfate (Liu and Roy, 1995). Both nonionic and ionic surfactants affect hydraulic conductivity reduction in loam and sand (Allred and Brown, 1994). Most organic compounds are surface-active in aqueous solution and can reduce water surface tension (Henry and Smith, 2002), and may change the contact angle of a porous material. Surfactants are used for remediation of the vadose zone or unconfined aquifers. Therefore, considering the effects of surfactants on water flow is important, and these effects must be evaluated by a proper water flow equation.

Because the liquid-solid contact angle is an index of soil wettability, it has been measured by the capillary rise method using Poiseuille's approximation (Letey et al., 1962), the Washburn equation (Michel et al, 2001; Goebel et al., 2004), or Darcy's law (Emerson and Bond, 1963; Nakaya et al., 1977). The contact angles of the fractions $<63 \mu \mathrm{m}$ and 63 to $100 \mu \mathrm{m}$ for sandy soil measured with the sessile drop method compared reasonably well with those measured with the capillary rise method (Bachmann et al., 2000).

However, the influence of surfactant concentration on infiltration in soils has not been evaluated exactly because of the diversity and complexity of soils. Because a surfactant changes water surface tension, the contact angle or wettability of a soil, and the soil hydraulic conductivity, such influences must be evaluated. The purpose of this study is to propose an equation for upward infiltration by capillary action under gravity based on Darcy's law, and to use the equation to determine the effect of an anionic surfactant on infiltration in porous materials. In order to accomplish the latter, we provide a theoretical 
explanation of the influences of an anionic surfactant on upward infiltration in glass beads, sand, leaf mold, peat moss, and polyethylene particles.

\section{MATERIALS AND METHODS}

\section{Materials}

We used glass beads (soda-lime glass BZ-01; As One Corp.), sand (Toyoura silica sand; Toyoura Keiseki Kogyo Corp.), leaf mold (as sold for general garden use), peat moss (as sold for general garden use), and polyethylene particles (Hi-zex MILLION 340 M; Mitsui Chemicals) for the experiments. Their physical characteristics are listed in Table 1 . The sand, leaf mold, and peat moss were sieved through a $0.85-\mathrm{mm}$ sieve, and the residue remaining on a $0.075-\mathrm{mm}$ sieve was used. The leaf mold and peat moss were crushed before sieving. Because the diameters of glass beads and polyethylene particles ranged between $0.075 \mathrm{~mm}$ and $0.250 \mathrm{~mm}$, they were used without sieving. The glass beads were washed with toluene, heated at $450^{\circ} \mathrm{C}$, and washed with $600 \mathrm{~mol} \mathrm{~m} \mathrm{~m}^{-3} \mathrm{HCl}$. All materials were washed with $1 \mathrm{~mol} \mathrm{~m}^{-3}$ $\mathrm{NaCl}$ and pure water, then dried in an oven at $30^{\circ} \mathrm{C}$ for about 24 hours before the experiments. The arithmetic mean radius of each material was obtained from the ratio of dry mass of each residue on a 0.425-mm sieve, a $0.250-\mathrm{mm}$ sieve, a $0.106-\mathrm{mm}$ sieve, and a $0.075-\mathrm{mm}$ sieve (no replication). Information on the density of the polyethylene particles was obtained from the manufacturer. The density of each of the other materials was determined using a pycnometer. The averages of triplicated data are listed in Table 1. The calculation method for porosity in Table 1 is described in the Methods section and those for equivalent pore radius and suction are described in the CAPILLARY INFILTRATION THEORY section.

\section{Methods}

Upward infiltration experiments were carried out according to the method of Nakaya et al. (1977). The experimental setup used in our study is shown in Fig. 1. Materials were packed into acrylic columns $2 \mathrm{~cm}$ in diameter and $60 \mathrm{~cm}$ in length. The bottom of the column was covered with filter paper. Four $15-\mathrm{cm}$-long columns were connected to form the $60-\mathrm{cm}$-long column. To ensure uniform packing, material was packed into the column in 5-cm layers with the calculated weight in order to assure the prescribed bulk density. The porosity of each material column was calculated from the bulk density and the particle density. Porosities of the packed materials are listed in Table 1. The uniformly packed material column was immersed in the solution. The solution was infiltrated from the bottom, and the distance of the infiltration front from the bottom was measured with a scale attached to the column. Distances to the highest position of the wetting front were determined at 1-minute intervals for a total duration of 20 minutes. The measurement interval was increased gradually after 20 minutes. The solution surface in 
which the material column was immersed was maintained at $0.2 \mathrm{~m} \pm 2 \mathrm{~mm}$ above the bottom of the column during the experiment by manually adding solution. The experiment was conducted at $25^{\circ} \mathrm{C}$. The upward infiltration experiment for each material was not replicated as the result (see Fig. 2) showed good characteristics as described in the RESULTS AND DISCUSSION section.

SDS was used because it has a simple structure, with an alkyl group and a negative charge. An anionic surfactant was chosen because many detergents are anionic and commonly anions are supposed to be less adsorptive than cations on soils. The SDS solutions were infiltrated into the experimental column, at concentrations of $0,3.5,7.0,21,70$, and $700 \mathrm{~mol} \mathrm{~m}^{-3}$. The critical micelle concentration (CMC) was 8.2 mol m$~^{-3}$ at $25^{\circ} \mathrm{C}$ (Chemical Society of Japan, 1984). In order to avoid any concentration change at an infiltration front caused by adsorption, a much larger SDS concentration, $700 \mathrm{~mol} \mathrm{~m}^{-3}$, than CMC was applied as one of the conditions. Surface tension of the solution was measured using the Wilhelmy method, and viscosity was measured with a rotation viscometer (Hiemenz, 1986). The measurement of surface tension was duplicated and that of viscosity was triplicated. The averaged values are listed in Table 2. Ethanol was also infiltrated in order to calculate advancing contact angles for the SDS solutions (Letey et al., 1962). The calculation method is given in the UPWARD INFILTRATION THEORY section using Eq.[3].

Swelling experiments were carried out in order to detect swelling phenomena during infiltration. The materials were packed into a 10 -cm-thick layer in the acrylic columns $2 \mathrm{~cm}$ in diameter. The bottom of the column was covered with filter paper. The densities of the packed materials were the same as those used in the upward infiltration experiments. Pure water or $700 \mathrm{~mol} \mathrm{~m}^{-3}$ SDS solution was infiltrated into each material column by capillary action and hydraulic head, and the column was saturated with the liquid until the water surface was observed on the upper surface of the material column. That is, the hydraulic head was generated beyond the height of the material column. After saturation was reached, the material thickness in the column was measured. The measurement was done once for each material.

The saturated material column prepared in the swelling experiment was used for the measurement of saturated hydraulic conductivity, which was conducted using the falling head method (Klute and Dirksen, 1986). The measurement was taken three times for each column. The measured values are given in Table 3.

\section{UPWARD INFILTRATION THEORY}

A fundamental upward infiltration equation is derived from the following Darcy's law (Emerson and Bond, 1963; Nakaya et al., 1977).

$$
q=\varepsilon v=\varepsilon \frac{d x}{d t}=k \frac{\Delta H}{x}
$$


where $q$ is the water flux density $\left(\mathrm{m}^{3} \mathrm{~m}^{-2} \mathrm{~s}^{-1}\right), \varepsilon$ is the volumetric water content $\left(\mathrm{m}^{3} \mathrm{~m}^{-3}\right), v$ is the pore water velocity $\left(\mathrm{m} \mathrm{s}^{-1}\right), x$ is the distance of the infiltration front from the inflow boundary of the column $(\mathrm{m}), t$ is time (s), $k$ is the saturated hydraulic conductivity $\left(\mathrm{m} \mathrm{s}^{-1}\right)$, and $\Delta H$ is the hydraulic head difference between the inflow boundary and the infiltration front $(\mathrm{m})$.

When we adopt the conditions of the upward infiltration experiment to Eq.[1], we get

$$
\begin{array}{r}
\varepsilon \frac{d x}{d t}=k \frac{L+h-x}{x} \\
h=\frac{2 \gamma \cos \theta}{\rho g r}
\end{array}
$$

where $L(=0.2 \mathrm{~m})$ is the depth of the bottom of the column from the water surface, $h$ is the suction at the infiltration front during infiltration $(\mathrm{m}), \gamma$ is the surface tension of the solution $\left(\mathrm{N} \mathrm{m}^{-1}\right), \theta$ is the advancing contact angle $\left({ }^{\circ}\right), \rho$ is the density of the solution $\left(\mathrm{kg} \mathrm{m}^{-3}\right), g$ is the gravitational acceleration $\left(9.81 \mathrm{~m} \mathrm{~s}^{-2}\right)$, and $r$ is the equivalent pore radius in the material column (m). Solving Eq.[2] under the condition when $x=0$ at $t=0$ and $x=x$ at $t=t$, we get

$$
\frac{\varepsilon}{k}[-x-(h+L) \log |-x+(h+L)|+(h+L) \log (h+L)]=t
$$

It should be noted that for a cylindrical tube, it can be shown that Eq.[4] is equivalent to the Washburn equation. The average velocity in a cylindrical tube, $v$, is

$$
v=\frac{\rho g r^{2}}{8 \mu} \frac{\Delta H}{x}
$$

where $r$ is the radius of the cylinder (m), and $\mu$ is the viscosity of the liquid (Ns $\mathrm{m}^{-2}$ ). Substituting Eq.[5] into Eq.[1], we get

$$
k=\frac{\varepsilon \rho g r^{2}}{8 \mu}
$$

When we consider $L=0 \mathrm{~m}$ and substituting Eq.[6] into Eq.[4], we get the following Washburn equation (Marmur, 2003).

$$
\frac{\rho g r^{2}}{8 \mu h} t=-\frac{x}{h}-\log \left(1-\frac{x}{h}\right)
$$

That is, this newly derived upward infiltration equation [4] is physically equivalent to the Washburn equation. Saturated hydraulic conductivity, $k$, does not explicitly appear in the Washburn equation. However, the new equation [4] contains $k$. Therefore, $k$ can be determined by using the new equation [4] as described later. Validity of the new equation [4] can be also evaluated by comparing calculated $k$ with measured $k$.

The advancing contact angle, $\theta$, can be calculated from Eq.[3] when $h$ and $\gamma$ are known. The values $h$ and $\varepsilon / k$ in Eq.[4] can be assumed to be constant values during saturated infiltration (Emerson and Bond, 

experimental values. The value $r$ in Eq.[3] was derived from the upward infiltration experiment for ethanol and calculation with Eq.[4], provided $\theta$ is 0 for ethanol (Letey et al., 1962): the $r$ was calculated with the derived $h$ and Eq.[3]. The calculated $r$ and $h$ for each material are listed in Table 1 and the calculated $\theta$ is listed in Table 2. The $h$ values indicate the suction at the infiltration front during infiltration as defined before.

Saturated hydraulic conductivity, $k$, in the upward infiltration experiment was evaluated using the derived value $\varepsilon / k$. In this calculation, porosity that was already derived was used instead of $\varepsilon$, assuming it was almost equal to $\varepsilon$.

\section{RESULTS AND DISCUSSION}

\section{Validity of the Upward Infiltration Equation}

The proposed upward infiltration equation [4] is a Green-Ampt Type equation. This type of equation has been found to apply quite satisfactorily for cases of infiltration into initially dry coarse-textured soils (Hillel, 1980). For cases of upward infiltration into dry sand, this type of theory agrees well with the experimental data collected when a saturated condition is maintained (Emerson and Bond, 1963; Tabuchi, 1995). When the infiltration front rises to some extent, large pore cells will become unsaturated and small pore cells will be saturated (Emerson and Bond, 1963). Then the suction at the infiltration front, $h$, the volumetric water content, $\varepsilon$, and the hydraulic conductivity, $k$, will change. Because we intend to apply the proposed upward infiltration equation [4] to saturated infiltration, the fitted parameters $h$ and $\varepsilon / k$ in Eq.[4] are constant during infiltration in the calculation. This condition cannot be applied to unsaturated infiltration. Saturated infiltration occurs only in the initial stage. Therefore, we calculated $x$ and $t$ by best fitting them with the measured values of the initial stage using Eq.[4].

The measured data and the calculated values for the upward infiltration experiments are shown in Fig. 2. The height of the infiltration front in Fig. 2 denotes the distance from the fixed water table as described in Fig. 1. The calculated values fitting the measured data are denoted by solid lines. Dotted lines continuing from the solid lines are calculated values by using the same equations as that used for the calculation of the solid lines. The dotted lines deviate from the measured data. The later deviation between calculated and measured values was probably due to unsaturated conditions. The lines are fitted with the measured values for $0 \mathrm{~mol} \mathrm{~m}^{-3}, 7 \mathrm{~mol} \mathrm{~m}^{-3}, 70 \mathrm{~mol} \mathrm{~m}^{-3}$, and $700 \mathrm{~mol} \mathrm{~m}^{-3} \mathrm{SDS}$ solutions. Fig. 2 shows that the solid lines agree well with measured data. Standard deviations of the heights of infiltration fronts and correlation ratios of the heights over time for solid lines were calculated from measured values. Standard deviations are less than $1 \mathrm{~cm}$. Correlation ratios are higher than 0.96 except for leaf mold at $700 \mathrm{~mol} \mathrm{~m}^{-3}$ and polyethylene particles at $21 \mathrm{~mol} \mathrm{~m}^{-3}$; correlation ratio of the former is 0.888 and that of the latter is 
0.669 .

187 However, a physical parameter such as saturated hydraulic conductivity must be checked to see whether the infiltration equation is of value. The measured and calculated saturated hydraulic conductivities are listed in Table 3. The calculated values at $0 \mathrm{~mol} \mathrm{~m}^{-3}$ are similar to the measured values; measured values for polyethylene particles are not available because water was not able to infiltrate under these conditions. The calculated values at $700 \mathrm{~mol} \mathrm{~m}^{-3}$ for glass beads, sand, peat moss, and polyethylene particles almost agree with the measured values, but that for leaf mold is 45 times larger than the measured value. Therefore, the calculated line for leaf mold at $700 \mathrm{~mol} \mathrm{~m}^{-3}$ is wrong.

The large difference between measured and calculated hydraulic conductivities for leaf mold is probably caused by swelling. The expansion ratio, the ratio of increased thickness to the initial thickness of the material column in the swelling experiment, for $700 \mathrm{~mol} \mathrm{~m}^{-3} \mathrm{SDS}$ solution is $4.3 \%$ larger than that for pure water; initial thickness is $10.0 \mathrm{~cm}$, saturated thickness with water is $10.4 \mathrm{~cm}$, and saturated thickness with $700 \mathrm{~mol} \mathrm{~m}^{-3} \mathrm{SDS}$ solution is $10.83 \mathrm{~cm}$. The difference is much larger than that noted with the other materials (Table 3). When the soil swells, larger pores tend to become smaller and soil permeability decreases.

The measured saturated hydraulic conductivities at $700 \mathrm{~mol} \mathrm{~m}^{-3}$ for the other materials are smaller than those at $0 \mathrm{~mol} \mathrm{~m}^{-3}$ because the liquid viscosity of $700 \mathrm{~mol} \mathrm{~m}^{-3} \mathrm{SDS}$ solution is 2.1 times larger than that of pure water; the saturated hydraulic conductivity is inversely proportional to the viscosity, as shown in Eq.[6]. Conversely, saturated hydraulic conductivity values are similar among SDS solutions at equal to or less than $70 \mathrm{~mol} \mathrm{~m}^{-3}$, because these solutions have very similar viscosities (Table 2). Calculated saturated hydraulic conductivities for glass beads and sand are almost the same. For leaf mold, conductivities are similar at $0 \mathrm{~mol} \mathrm{~m}^{-3}, 3.5 \mathrm{~mol} \mathrm{~m}^{-3}$, and $7 \mathrm{~mol} \mathrm{~m}^{-3}$. When saturation, water flow path, and liquid viscosity are the same among different SDS solutions, hydraulic conductivity is a constant value. However, for leaf mold at $21 \mathrm{~mol} \mathrm{~m}^{-3}$ and $70 \mathrm{~mol} \mathrm{~m}^{-3}$ the value does not remain constant. This result indicates that pore structure changes when concentration exceeds $7 \mathrm{~mol} \mathrm{~m}^{-3}$, and that the swelling of leaf mold probably affects pore structure. In fact, upward infiltration becomes considerably slower at concentrations greater than $7 \mathrm{~mol} \mathrm{~m}^{-3}$ (Fig. 2(c)). For hydrophobic materials (polyethylene particles and peat moss), the calculated hydraulic conductivities fluctuate among different SDS concentrations. These results probably indicate the differences in saturation and water flow path at different concentrations, because infiltration into smaller pores may become difficult when the obtuse contact angle becomes larger.

The hydraulic conductivity and correlation ratio results show that the upward infiltration equation is very appropriate for glass beads and sand. It is also appropriate for leaf mold at equal to and less than 7 $\mathrm{mol} \mathrm{m}{ }^{-3}$, peat moss at $0 \mathrm{~mol} \mathrm{~m}^{-3}$ and $700 \mathrm{~mol} \mathrm{~m}^{-3}$, and polyethylene particles at $700 \mathrm{~mol} \mathrm{~m}^{-3}$. 
The calculated advancing contact angles derived with the upward infiltration equation are listed in Table 2. Several contact angles are omitted in Table 2 for cases in which the upward infiltration equation is not appropriate. Those for leaf mold at $21 \mathrm{~mol} \mathrm{~m}^{-3}, 70 \mathrm{~mol} \mathrm{~m}^{-3}$, and $700 \mathrm{~mol} \mathrm{~m}^{-3}$ are omitted because the pore structures changed during infiltration due to swelling. That for peat moss at $70 \mathrm{~mol} \mathrm{~m}$ is omitted because it could not be calculated: $\cos \theta$ in Eq.[3] became larger than 1.0 in calculation. As noted in the UPWARD INFILTRATION THEORY section, the contact angle, $\theta$, can be calculated from Eq.[3] when $h$ and $\gamma$ are known. $h$ is determined by a best fit of the measured values. $\gamma$ used in these calculations, along with the resulting $\theta$ (shown with no parentheses or dagger), for each SDS concentration are listed in Table 2. For calculations using the surface tension of pure water $\left(\gamma=72 \mathrm{mN} \mathrm{m}^{-1}\right)$, a dagger was added to the resulting $\theta$. For calculations made with both the $\gamma$ for pure water and that corresponding to the SDS concentration, parentheses are added to $\theta$ values in Table 2 .

When SDS is adsorbed on a material, the concentration of the infiltration front is smaller than the influent concentration. The influence on $\gamma$ must be considered in this case. Because SDS has a hydrophobic tail, adsorption by hydrophobic interaction occurs in organic materials. Therefore, the influence is considered for leaf mold, polyethylene particles, and peat moss. The influence must be considered for sand because it has $0.5 \%$ organic matter. In fact, the measured heights of the infiltration front for $0 \mathrm{~mol} \mathrm{~m}^{-3}, 3.5 \mathrm{~mol} \mathrm{~m}^{-3}, 7 \mathrm{~mol} \mathrm{~m}^{-3}$, and $21 \mathrm{~mol} \mathrm{~m}^{-3}$ solutions are almost the same for sand (Fig. 2(b)). In these cases, the SDS concentration at the infiltration front was supposed to become almost 0 mol $\mathrm{m}^{-3}$, because SDS was adsorbed on sand during infiltration. Then their infiltration rates became similar. For leaf mold, the measured heights of the infiltration front for $0 \mathrm{~mol} \mathrm{~m}^{-3}$ and $3.5 \mathrm{~mol} \mathrm{~m}^{-3}$ solutions are almost the same (Fig. 2(c)) due to the effect of adsorption. Therefore, $\gamma=72 \mathrm{mN} \mathrm{m}^{-1}$ was also used for calculating $\theta$ for $3.5 \mathrm{~mol} \mathrm{~m}^{-3}$ solution. In leaf mold for $7 \mathrm{~mol} \mathrm{~m}^{-3}$ solution, the result was the same when either $\gamma=72 \mathrm{mN} \mathrm{m}^{-1}$ or $\gamma=38 \mathrm{mN} \mathrm{m}^{-1}$ was used, because $\theta$ was $90^{\circ}$. For both peat moss and polyethylene particles, both surface tensions of pure SDS concentrations and $\gamma=72 \mathrm{mN} \mathrm{m}^{-1}$ were used, because the concentrations at the infiltration fronts were unknown. The expected contact angle ranges are listed in parentheses in Table 2 in these cases. In addition, as mentioned in the Validity of the Upward Infiltration Equation section, the calculated hydraulic conductivities under these conditions fluctuate. These results indicate differences in saturation and water flow path at different concentrations. Because the calculation of $\theta$ is based on the same saturation and water flow path conditions as that for ethanol infiltration, these calculated values are not very reliable.

The methods of contact angle calculation which use this upward infiltration equation and the 
advancing contact angle of low surface tension liquid is not always $0^{\circ}$ (Siebold, 2000). However, these methods are preferable to any technique for porous materials. (Hiemenz, 1986).

\section{Influence of Wettability on Infiltration of Pure Water and $700 \mathrm{~mol} \mathrm{~m}^{-3}$ SDS Solution}

The measured heights of infiltration front for pure water (Fig. 3) are in the descending order of glass material, the higher is the infiltration front (Table 2). This result indicates that the influence of contact angle or wettability is larger than the differences in average particle sizes (Table 1). At an early stage, the heights of infiltration front for glass beads are smaller than those for sand, probably because of the smaller pores for glass beads: saturated hydraulic conductivity becomes smaller with smaller pores. Pure water infiltrates well into hydrophilic materials and infiltrates poorly into hydrophobic materials. Pure water cannot infiltrate into the polyethylene particles even at a $20-\mathrm{cm}$ water head. Nakaya et al. (1977) indicated that the height of infiltration front decreased with the increase in coated humic acid on quartz sand. Because the coating of humic acid increases hydrophobicity, this result agrees with our result. The measured height for peat became larger than $0 \mathrm{~cm}$ after $200 \mathrm{~min}$ even though the calculated contact angle is $99^{\circ}$. This result indicates that the peat surface at the infiltration front became hydrophilic during measurement. Michel et al. (2001) demonstrated the change from hydrophilicity to hydrophobicity during desiccation of peat. Our result corresponds to their result.

Conversely, the measured heights of infiltration fronts for $700 \mathrm{~mol} \mathrm{~m}^{-3}$ SDS solution are similar for all media except for leaf mold (Fig. 4). The surfactant, which is amphipathic, decreased the contact angles for the hydrophobic materials, and the contact angles became similar among the materials (Table 2). Even hydrophobic materials become wettable with surfactant.

The height of infiltration front in leaf mold for $700 \mathrm{~mol} \mathrm{~m}^{-3}$ SDS solution is by far the lowest due to the very low level of saturated hydraulic conductivity (See the measured value in Table 3), which is probably caused by swelling. Such structural change in the leaf mold restricted solution infiltration.

\section{Impact of SDS Concentration}

\section{Effect of Surface Tension}

For the hydrophilic materials (glass beads and sand) the heights of infiltration fronts decrease with increasing SDS concentration because of the decrease in suction (Fig. 2(a), (b)). The suction decreases with the increase of SDS concentration, because the surface tension decreases with the increase in SDS concentration; the relationship between suction and surface tension is given in Eq.[3]. Because the advancing contact angles do not differ much among different SDS concentrations (see in Table 2), surface 
(1962) who used a wetting agent for quartz sand. However, they did not compare different concentrations of wetting agent.

290 For leaf mold, the height of infiltration front also decreases with increasing SDS concentration (Fig. 2(c)). The contact angle for $0 \mathrm{~mol} \mathrm{~m}^{-3}$ is $84^{\circ}$, slightly acute. Therefore, the decrease of surface tension with the concurrent increase of SDS concentration may cause the decrease in height. However, the influence of swelling is supposed to be more significant when the concentration increases.

For hydrophobic materials (polyethylene particles and peat moss) the heights of infiltration fronts increase with increasing SDS concentration because of the increase in suction, except for $700 \mathrm{~mol} \mathrm{~m}^{-3}$ SDS solution (Fig. 2(d),(e)). The suction increases with the increase in SDS concentration, because the surface tension decreases with the increase in SDS concentration and $\cos \theta$ is negative when $\theta$ is obtuse; the relationship between suction and surface tension is given in Eq.[3]. The influence of suction on the height of infiltration front is depicted in Fig. 5. The solid lines are the calculated values with the same $\theta\left(=110^{\circ}\right)$ and a different $\gamma$. In the calculations with Eq.[4], $\varepsilon / k=(\varepsilon / k)_{700} \times(0.89 / 1.89)$ was used. $(\varepsilon / k)_{700}$ is the obtained value when the calculated values were fitted with the measured values at $700 \mathrm{~mol} \mathrm{~m}^{-3}$ SDS solution. The data for $700 \mathrm{~mol} \mathrm{~m}^{-3}$ SDS solution are supposed to be most suitable because the material becomes wettable. Therefore, $(\varepsilon / k)_{700}$ was chosen. However, the solution viscosity was modified to 0.89 $\mathrm{Pa} \cdot \mathrm{s}$ by multiplying by $0.89 / 1.89$ in order to compare the data for 0 to $70 \mathrm{~mol} \mathrm{~m}^{-3} \mathrm{SDS}$ solution. The calculated result indicates that the height increases with the decrease in surface tension. However, the change in surface tension cannot completely explain the increased height; the measured increase is much larger than the calculated increase. In the case of $700 \mathrm{~mol} \mathrm{~m}^{-3} \mathrm{SDS}$ solution, the height is smaller in the initial stages due to the high viscosity, as mentioned before. In the later stages, the heights of infiltration fronts become highest for polyethylene particles and the second highest for peat moss, because of the wettability.

\section{Effect of Contact Angle}

For the hydrophilic materials (glass beads and sand), the advancing contact angles differ little among different SDS concentrations (see in Table 2). For sand, they are almost same from $0 \mathrm{~mol} \mathrm{~m}^{-3}$ to $70 \mathrm{~mol}$ $\mathrm{m}^{-3}$. For glass beads, there is no simple increase or decrease with increasing SDS concentration. As discussed before, the contact angles are not a major cause of the decrease in height of infiltration front with the increase in SDS concentration. For the leaf mold, because the contact angles are around $90^{\circ}$ for 0 $\mathrm{mol} \mathrm{m} \mathrm{m}^{-3}, 3.5 \mathrm{~mol} \mathrm{~m}^{-3}$ and $7 \mathrm{~mol} \mathrm{~m}^{-3}$ solutions, their influence following the change in SDS concentration is also not significant. At concentrations higher than $7 \mathrm{~mol} \mathrm{~m}^{-3}$ for leaf mold, the effect of swelling is supposed to be most significant, as discussed before.

For the hydrophobic materials (polyethylene particles and peat moss), the effect of contact angles are 
significant. The contact angles for these materials become smaller with an increase in SDS concentration, which causes the increase in height of the infiltration front. The materials become wettable with increasing SDS concentration, because the surfactant is amphipathic. In Fig. 6, the measured heights of infiltration fronts and those calculated with $\gamma=38 \mathrm{mN} \mathrm{m}^{-1}$, in addition to the different advancing contact angle in the polyethylene particles, are shown. In the calculations with Eq.[4], $\varepsilon / k=(\varepsilon / k)_{700} \times(0.89 / 1.89)$ was also used in order to compare the data for 0 to $70 \mathrm{~mol} \mathrm{~m}^{-3} \mathrm{SDS}$ solution, as mentioned before. The result clearly shows that the influence of the contact angle on the height is significant. In fact, the obtained advancing contact angles for $700 \mathrm{~mol} \mathrm{~m} \mathrm{~m}^{-3} \operatorname{SDS}\left(\theta=69^{\circ}\right.$ for polyethylene particles, $\theta=43^{\circ}$ for peat moss $)$ are much smaller than those for $0 \mathrm{~mol} \mathrm{~m}^{-3} \operatorname{SDS}\left(\theta>125^{\circ}\right.$ for polyethylene particles, $\theta=102^{\circ}$ for peat moss). Pelishek et al. (1962) showed a similar effect of the wetting agent on infiltration in the materials whose contact angles with pure water were $72^{\circ}$ and $83^{\circ}$. We also show that a decrease in surface tension with an increase in the SDS concentration also increases the height of the infiltration front.

\section{Influence of Adsorption}

Anionic surfactants adsorb on soils via hydrophobic interaction (Atay et al., 2000). The adsorption affected infiltration rate in our experiment. In sand for 3.5, 7.0 and $21 \mathrm{~mol} \mathrm{~m}^{-3}$ SDS solution and leaf mold for $3.5 \mathrm{~mol} \mathrm{~m}^{-3} \mathrm{SDS}$ solution, the heights of infiltration fronts become almost the same as those for $0 \mathrm{~mol}$ $\mathrm{m}^{-3}$ SDS solution. These results suggest an influence of SDS adsorption on the materials, as previously noted. The retardation of anionic surfactant from the wetting front due to adsorption in loamy sand was reported by Allred and Brown (1996). In our research, the SDS concentration of the infiltration front is supposed to decrease due to adsorption on the soils, and then surface tension increases. Thus the infiltration rate of the SDS solution becomes the same as that of pure water. In peat moss, the influence of adsorption on the height is observed at $3.5 \mathrm{~mol} \mathrm{~m}^{-3}$; the height for $3.5 \mathrm{~mol} \mathrm{~m}^{-3} \mathrm{SDS}$ solution is similar to that for $0 \mathrm{~mol} \mathrm{~m}^{-3} \mathrm{SDS}$ solution (Fig. 2(e)).

In leaf mold, the saturated hydraulic conductivity decreases when the SDS solution at a higher concentration infiltrates. The swelling of the material induces a decrease in hydraulic conductivity. The increases in the heights of infiltration fronts for $21 \mathrm{~mol} \mathrm{~m}^{-3}$ and $70 \mathrm{~mol} \mathrm{~m}^{-3} \mathrm{SDS}$ are restricted in the initial stages, and that for $700 \mathrm{~mol} \mathrm{~m}^{-3}$ is restricted in all stages (Fig. 2(c)). These trends are probably due to the low saturated hydraulic conductivity caused by swelling. The heights for $21 \mathrm{~mol} \mathrm{~m}^{-3}$ and $70 \mathrm{~mol} \mathrm{~m}^{-3} \mathrm{SDS}$ increase at the later stage, probably because the concentrations are too low for enough adsorption to generate sufficient swelling and maintain low hydraulic conductivity. The swelling mechanism for leaf mold can probably be attributed to electrostatic repulsive force caused by adsorbed anionic surfactant. However, more research is needed to clarify this point.

Hydraulic conductivity reductions for loam (Allred and Brown, 1994) and silty clay loam (Liu and 
Roy, 1995) caused by SDS were reported by other researchers. Liu and Roy (1995) suggested that the reduction was mainly caused by the $\mathrm{Ca}$ surfactant precipitation. In our experiment, however, the precipitation with divalent cations such as Ca did not occur because divalent cations had been removed before the experiment.

Conversely, the measured hydraulic conductivity of peat moss for $700 \mathrm{~mol} \mathrm{~m}^{-3}$ does not become much smaller than that for $0 \mathrm{~mol} \mathrm{~m} \mathrm{~m}^{-3}$, although both peat moss and leaf mold are organic soils. The expansion ratios for peat moss differ little between those at $0 \mathrm{~mol} \mathrm{~m}^{-3} \mathrm{SDS}$ and at $700 \mathrm{~mol} \mathrm{~m}^{-3} \mathrm{SDS}$, while those for leaf mold differ quite noticeably (Table 3). The different results for leaf mold and peat moss probably arise from the difference in adsorption and structural stability.

\section{SUMMARY AND CONCLUSIONS}

We proposed an upward infiltration equation based on Darcy's law. The infiltration equation was shown to be equivalent to the Washburn equation. The values calculated using the equation showed good agreement with the measured infiltration values, especially for the inorganic materials (glass beads and sands).

By using the new equation, we evaluated the influence of the anionic surfactant (SDS) on infiltration in porous materials. Saturated hydraulic conductivity and the material expansion ratio were also measured for the evaluation. Consequently, the infiltration could be explained well theoretically using values for surface tension and contact angle, which are affected by SDS concentration.

In glass beads and sand, which are hydrophilic inorganic materials, the infiltration rate decreased as the SDS concentration increased due to the decrease in solution surface tension. No major change in the contact angle was observed. The upward infiltration equation explained this infiltration well. In polyethylene particles and peat moss, which are hydrophobic organic materials, the infiltration rate increased as the SDS concentration increased because of the decrease in the contact angle and surface tension.

In leaf mold, the saturated hydraulic conductivity became much lower at higher SDS concentrations, whereas in peat moss, also an organic material, such change was not observed. Their surface characteristics may differ with respect to interaction with an anionic surfactant. Further investigation is needed to clarify this point.

Because soils are diverse and complex, the influence of surfactants on infiltration may vary. The simple experiments and the upward infiltration equation which we applied to the analysis of the experimental data are useful. Since surfactants significantly affect the physicochemical nature of the soil surface, it is worth performing basic research to further understand and improve the technical use of surfactants in applications such as soil remediation. Large amounts of surfactants are discharged as 
municipal or industrial wastes. Moreover, most organic compounds are surface-active in aqueous solution. Therefore, those surfactants could potentially influence water flow in soils.

\section{REFERENCES}

Allred, B., and G.O. Brown. 1994. Surfactant-induced reductions in soil hydraulic conductivity. Ground Water Monit. Rem. 14:174-184.

Allred, B., and G.O. Brown. 1996. Anionic surfactant transport characteristics in unsaturated soil. Soil Sci. 161:415-425.

Atay, N.Z., O. Yenigün, and M. Asutay. 2000. Sorption of anionic surfactants SDS, AOT and cationic surfactant Hyamine 1622 on natural soils. Water Air Soil Pollut. 136:55-67.

Bachmann, J., R. Horton, R.R. van der Ploeg, and S. Woche. 2000. Modified sessile drop method assessing initial soil-water contact angle of sandy soil. Soil Sci. Soc. Am. J. 64:564-567.

Chemical Society of Japan. 1984. Chemistry handbook, (In Japanese.) I. p. 571. Maruzen, Tokyo.

Cisar, J.L., K.E. Williams, H.E. Vivas, and J.J. Haydu. 2000. The occurrence and alleviation by surfactants of soil-water repellency on sand-based turfgrass systems. J. Hydrology. (Amsterdam) 231/232:352-358.

Emerson, W.W., and R.D. Bond. 1963. The rate of water entry into dry sand and calculation of the advancing contact angle. Australian J. Soil Res. 1:9-16.

Feng, G.L., J. Letey, and L. Wu. 2002. The influence of two surfactants on infiltration into a water-repellent soil. Soil Sci. Soc. Am. J. 66:361-367.

Goebel, M.-O., J. Bachmann, S.K. Woche, W.R. Fischer, and R. Horton. 2004. Water potential and aggregate size effects on contact angle and surface energy. Soil Sci. Soc. Am. J. 68:383-393.

Henry, E.J., J.E. Smith, and A.W. Warrick. 1999. Solubility effects on surfactant-induced flow through porous media. J. Hydrol. 223:164-174.

Henry, E.J., and J.E. Smith. 2002. The effect of surface-active solutes on water flow and contaminant transport in variably saturated porous media with capillary fringe effects. J. Contam. Hydrol. $56: 247-270$.

Hiemenz, P.C. 1986. The viscosity of dilute dispersions. p. 169-222. Surface tension and contact angle. p. 287-352. In P.C. Hiemenz (ed.) Principles of colloid and surface chemistry. Marcel Dekker, New York.

Hillel, D. 1980. The Green and Ampt approach. p.13-16. In D. Hillel (ed.) Applications of Soil Physics. Academic Press, New York. 
Karkare, V.M., and T. Fort. 1993. Water movement in "unsaturated" porous media due to pore size and surface tension induced capillary pressure gradients. Langmuir 9, 2398-2403.

Klute, A., and C. Dirksen. 1986. Hydraulic conductivity and diffusivity: Laboratory methods. p. 687-734. In A. Klute (ed.) Methods of soil analysis, Part 1. Physical and mineralogical methods. ASA, Madison, WI.

Koopal, L.K., T. Goloub, A. de Keizer, and M.P. Sidorova. 1999. The effect of cationic surfactants on wetting, colloid stability and flotation of silica. Colloids Surf. A. 151:15-25.

Kostka, S. J. 2000. Amelioration of water repellency in highly managed soils and the enhancement of turfgrass performance through the systematic application of surfactants. J. Hydrology. (Amsterdam) 231/232:359-368.

Letey, J., J. Osborn, and R.E. Pelishek. 1962. Measurement of liquid-solid contact angles in soil and sand. Soil Sci. 93:149-153.

Lewis, M.A. 1991. Chronic and sublethal toxicities of surfactants to aquatic animals: a review and risk assessment. Water Res. 25: 101-113.

Liu, M., and D. Roy. 1995. Surfactant-induced interactions and hydraulic conductivity changes in soil. Waste Manage. 15:463-470.

Marmur, A. 2003. Kinetics of penetration into uniform porous media: Testing the equivalent-capillary concept. Langmuir 19:5956-5959.

Michel, J.-C., L.-M. Rivière, and M.-N. Bellon-Fontaine. 2001, Measurement of the wettability of organic materials in relation to water content by the capillary rise method. Eur. J. Soil Sci. 52:459-467.

Miller, W.W., N. Valoras, and J. Letey. 1975. Movement of two nonionic surfactants in wettable and water-repellent soils. Soil Sci. Soc. Proc. 39:11-16.

Mustafa, M.A., and J. Letey. 1969. The effect of two nonionic surfactants on aggregate stability of soils. Soil Sci. 107:343-347.

Nakaya, N., H. Yokoi, and H. Motomura. 1977. The method for measuring of water repellency of soil. Soil Sci. Plant Nutr. (Tokyo) 23:417-426.

Pelishek, R. E., J. Osborn, and J. Letey. 1962. The effect of wetting agents on infiltration. Soil Sci. Soc. Am. Proc. 26:595-598.

Sakashita, S. 1979. Electron microscopic study of liver tissue after cutaneous administration of detergents. J. Clin. Electron Microscopy. 12:189-216.

Siebold, A., M. Nardin, J. Schultz, A. Walliser, and M. Oppliger. 2000. Effect of dynamic contact angle on capillary rise phenomena. Colloids and Surfaces A 161:81-87.

Smith, J.E., and R.W. Gillham. 1994. The effect of concentration-dependent surface tension on the flow of water and transport of dissolved organic compounds: a pressure head-based formulation and 
numerical model. Water Resour. Res. 30:343-354.

459 Smith, J.E., and R.W. Gillham. 1999. Effects of solute-concentration-dependent surface tension on 460 unsaturated flow: laboratory and column experiments. Water Resour. Res. 35:973-982.

461 Tabuchi, T. 1995. Water flow through soils. p.257-323. In S. Iwata, T. Tabuchi and B. Warkentin (ed.) 462 Soil-water interactions, Mechanisms and applications. Marcel Dekker, New York.

463 West, C.C., and J.H. Harwell. 1992. Surfactants and subsurface remediation. Environ. Sci. Technol. 26: 464 2324-2330.

465 
468 Fig. 1 Schematic diagram of the setup for upward infiltration experiment.

470 Fig. 2 Height of infiltration front during upward infiltration of SDS (sodium dodecyl sulfate) solution.

471 Symbols are measured values. Solid lines are calculated values fitted with measured data. Dotted lines are

472 calculated values that follow solid lines. The lines are fitted with the measured values for $0 \mathrm{~mol} \mathrm{~m}^{-3}, 7 \mathrm{~mol}$

$473 \mathrm{~m}^{-3}, 70 \mathrm{~mol} \mathrm{~m}^{-3}$ and $700 \mathrm{~mol} \mathrm{~m}^{-3} \mathrm{SDS}$ solutions.

475 Fig. 3. Height of infiltration front during pure water infiltration.

476

477 Fig. 4. Height of infiltration front during $700 \mathrm{~mol} \mathrm{~m}^{-3}$ SDS solution infiltration.

Fig. 5. Height of infiltration front in the polyethylene particles column. Solid lines are the calculated 480 curves with different surface tensions and the same advancing contact angle $\left(\theta=110^{\circ}\right)$.

Fig. 6. Height of infiltration front in the polyethylene particles column. Solid lines are the calculated curves with different advancing contact angles and the same surface tension $\left(\gamma=38 \mathrm{mN} \mathrm{m}^{-1}\right)$. 
Table 1. Physical properties of the materials used for the upward infiltration experiments.

\begin{tabular}{|c|c|c|c|c|c|c|c|}
\hline \multirow[b]{2}{*}{ Material } & \multirow[b]{2}{*}{ Mean radius } & \multirow[b]{2}{*}{$\begin{array}{l}\text { Particle } \\
\text { density }\end{array}$} & \multirow[b]{2}{*}{ Porosity } & \multirow[b]{2}{*}{$\begin{array}{c}\text { Organic } \dagger \\
\text { matter }\end{array}$} & \multirow[b]{2}{*}{$\begin{array}{l}\text { Equivalent } \\
\text { pore radius }\end{array}$} & \multicolumn{2}{|c|}{ Suction $h$} \\
\hline & & & & & & $\begin{array}{c}0 \mathrm{~mol} \mathrm{~m}^{-3} \\
\mathrm{SDS}+\end{array}$ & $\begin{array}{c}700 \mathrm{~mol} \mathrm{~m}^{-3} \\
\mathrm{SDS}+\end{array}$ \\
\hline & $\mathrm{mm}$ & $\mathrm{g} \mathrm{cm}^{-3}$ & $\%$ & $\%$ & $\mathrm{~mm}$ & $\mathrm{~cm}$ & $\mathrm{~cm}$ \\
\hline Glass beads & 0.06 & 2.47 & 40.5 & 0 & 0.027 & 21.8 & 6.97 \\
\hline Sand & 0.18 & 2.67 & 46.9 & 0.5 & 0.034 & 13.6 & 6.17 \\
\hline Leaf mold & 0.15 & 1.75 & 74.9 & 100 & 0.080 & 2.5 & - \\
\hline Peat moss & 0.12 & 1.55 & 91.6 & 100 & 0.050 & -3.5 & 5.56 \\
\hline Polyethylene particles & 0.08 & $0.93 \dagger$ & 35.5 & 100 & 0.042 & $<-20$ & 6.37 \\
\hline
\end{tabular}

$\dagger$ Data from producers

†SDS, sodium dodecyl sulfate 
Table 2. Calculated advancing contact angles, surface tensions and viscosities of SDS solutions. Contact angles in ( ) were calculated using the surface tensions at $0 \mathrm{~mol} \mathrm{~m}^{-3}$ and the influent concentration because the concentration at the infiltration front was unknown.

\begin{tabular}{|c|c|c|c|c|c|c|}
\hline & \multicolumn{6}{|c|}{ SDS concentration } \\
\hline & $0 \mathrm{~mol} \mathrm{~m}^{-3}$ & $3.5 \mathrm{~mol} \mathrm{~m}^{-3}$ & $7 \mathrm{~mol} \mathrm{~m}^{-3}$ & $21 \mathrm{~mol} \mathrm{~m}^{-3}$ & $70 \mathrm{~mol} \mathrm{~m}^{-3}$ & $700 \mathrm{~mol} \mathrm{~m}^{-3}$ \\
\hline \multicolumn{7}{|l|}{ Advancing contact angle } \\
\hline Glass beads & $36^{\circ}$ & $30^{\circ}$ & $28^{\circ}$ & $43^{\circ}$ & $45^{\circ}$ & $60^{\circ}$ \\
\hline Sand & $51^{\circ}$ & $50^{\circ} \dagger$ & $52^{\circ} \dagger$ & $50^{\circ} \dagger$ & $49^{\circ}$ & $57^{\circ}$ \\
\hline Leaf mold & $82^{\circ}$ & $85^{\circ} \dagger$ & $90^{\circ}$ & - & - & - \\
\hline Peat moss & $102^{\circ}$ & $\left(112-124^{\circ}\right)$ & $\left(101-110^{\circ}\right)$ & $\left(94-97^{\circ}\right)$ & - & $43^{\circ}$ \\
\hline Polyethylene particles & $>125^{\circ}$ & $\left(107-117^{\circ}\right)$ & $\left(109-127^{\circ}\right)$ & $\left(103-116^{\circ}\right)$ & $\left(92-93^{\circ}\right)$ & $69^{\circ}$ \\
\hline Surface tension $\mathrm{mN} \mathrm{m}^{-1}$ & 72 & 47 & 39 & 38 & 38 & 38 \\
\hline Viscosity & 0.89 & - & - & 0.91 & 0.99 & 1.89 \\
\hline Solution density $\mathrm{kg} \mathrm{m}^{-3}$ & $1.00 \times 10^{3}$ & $1.00 \times 10^{3}$ & $1.00 \times 10^{3}$ & $1.00 \times 10^{3}$ & $1.00 \times 10^{3}$ & $1.03 \times 10^{3}$ \\
\hline
\end{tabular}


Table 3. Expansion ratios and measured saturated hydraulic conductivities of the material columns with $10-\mathrm{cm}$ length, and calculated saturated hydraulic conductivities.

\begin{tabular}{|c|c|c|c|c|c|c|c|c|c|c|}
\hline \multirow[b]{3}{*}{ SDS conc. } & \multirow{2}{*}{\multicolumn{4}{|c|}{$\begin{array}{c}\text { Measured } \\
\text { saturated hydraulic } \\
\text { conductivity } \\
-\mathrm{mol} \mathrm{m}^{-3}-\end{array}$}} & \multicolumn{6}{|c|}{ Calculated saturated hydraulic conductivity } \\
\hline & & & & & \multirow[b]{2}{*}{0} & \multirow{2}{*}{\multicolumn{2}{|c|}{7}} & \multirow[t]{2}{*}{$\mathrm{m}^{-3}-$} & \multirow[b]{2}{*}{70} & \multirow[b]{2}{*}{700} \\
\hline & 0 & 700 & 0 & 700 & & & & & & \\
\hline & 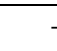 & - & $-\mathrm{cr}$ & $-1-$ & 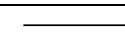 & 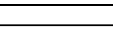 & $\mathrm{Cl}^{\mathrm{c}}$ & $\mathrm{s}^{-1}-$ & & 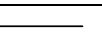 \\
\hline Glass beads & -0.3 & -0.3 & $1.1 \times 10^{-2}$ & $3.2 \times 10^{-3}$ & $7.4 \times 10^{-3}$ & $6.8 \times 10^{-3}$ & $7.3 \times 10^{-3}$ & $8.3 \times 10^{-3}$ & $6.8 \times 10^{-3}$ & $2.3 \times 10^{-3}$ \\
\hline Sand & -0.1 & -1.3 & $3.0 \times 10^{-2}$ & $7.5 \times 10^{-3}$ & $3.3 \times 10^{-2}$ & $3.4 \times 10^{-2}$ & $2.9 \times 10^{-2}$ & $2.8 \times 10^{-2}$ & $3.1 \times 10^{-2}$ & $7.9 \times 10^{-3}$ \\
\hline Leaf mold & 4.0 & 8.3 & $1.6 \times 10^{-2}$ & $4.9 \times 10^{-4}$ & $1.5 \times 10^{-2}$ & $1.5 \times 10^{-2}$ & $1.3 \times 10^{-2}$ & $6.0 \times 10^{-3}$ & $2.4 \times 10^{-2}$ & $2.2 \times 10^{-2}$ \\
\hline Peat moss & 3.7 & 4.3 & $1.3 \times 10^{-2}$ & $8.2 \times 10^{-3}$ & $1.3 \times 10^{-2}$ & $2.7 \times 10^{-2}$ & $4.2 \times 10^{-2}$ & $3.4 \times 10^{-2}$ & $2.1 \times 10^{-2}$ & $4.1 \times 10^{-3}$ \\
\hline $\begin{array}{c}\text { Polyethylene } \\
\text { particles }\end{array}$ & - & 2.7 & - & $3.8 \times 10^{-3}$ & - & $1.6 \times 10^{-3}$ & $3.9 \times 10^{-3}$ & $6.5 \times 10^{-3}$ & $1.2 \times 10^{-2}$ & $2.2 \times 10^{-3}$ \\
\hline
\end{tabular}




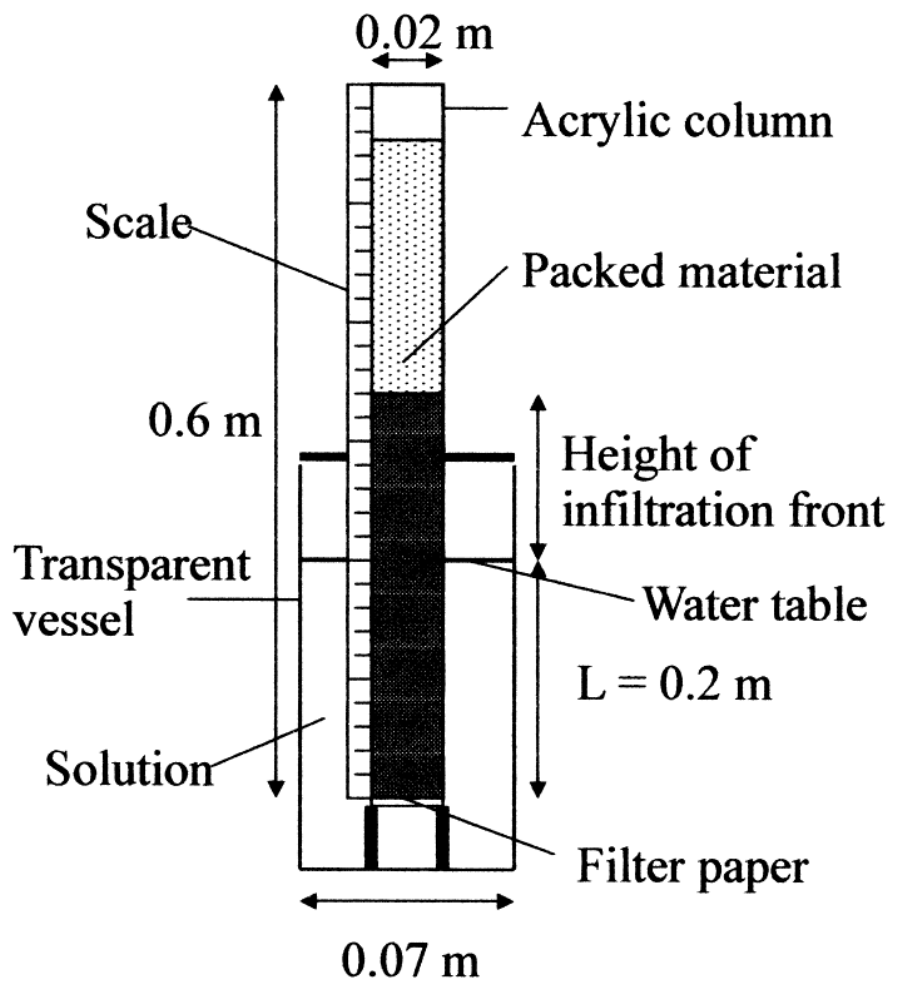

Fig. 1 Schematic diagram of the setup for upward infiltration experiment. 

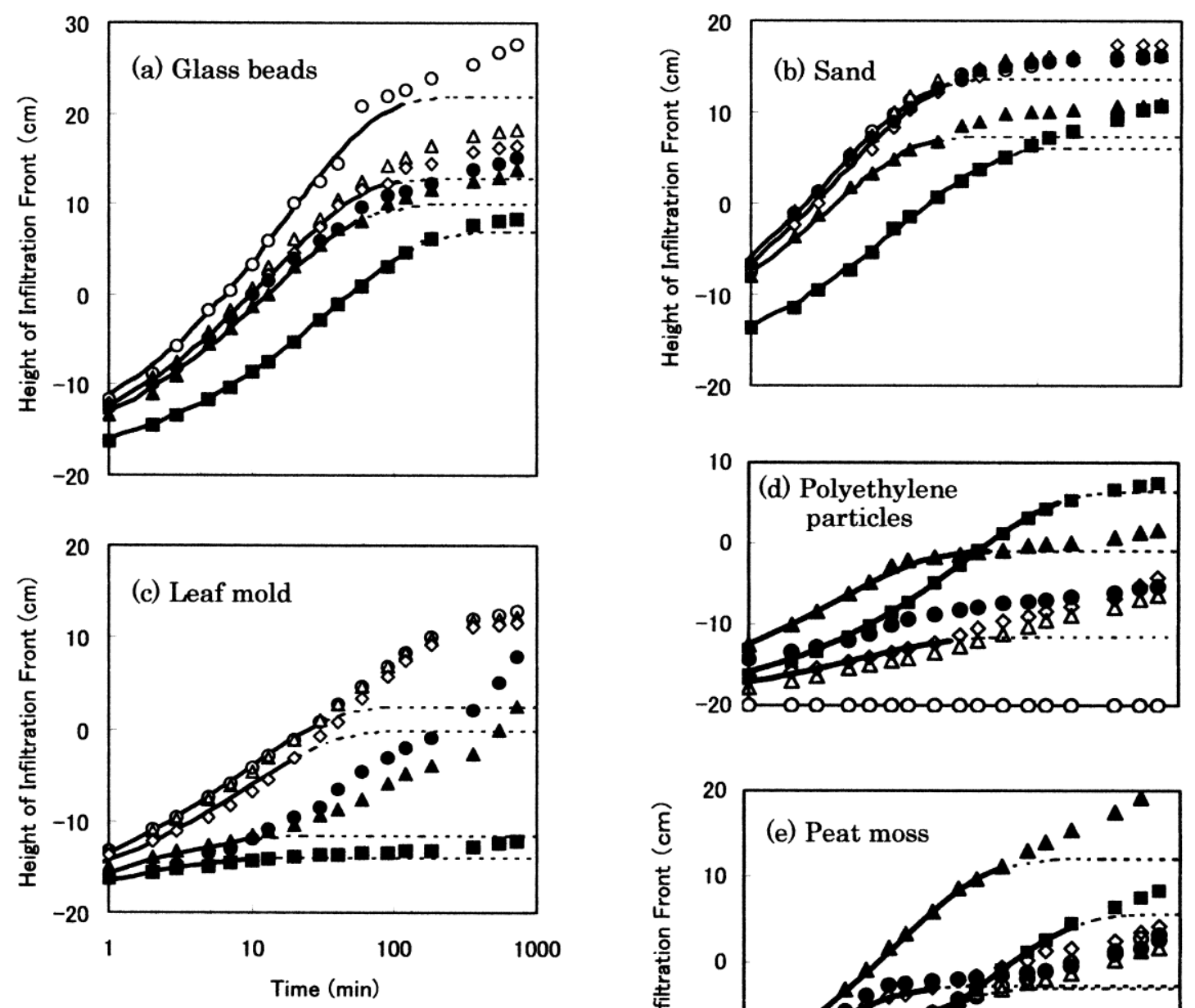

$\bigcirc 0 \mathrm{~mol} \mathrm{~m}^{-3}, \triangle 3.5 \mathrm{~mol} \mathrm{~m}^{-3}, \diamond 7 \mathrm{~mol} \mathrm{~m}^{-3}$,

$\bigcirc 21 \mathrm{~mol} \mathrm{~m}^{-3}, \Delta 70 \mathrm{~mol} \mathrm{~m}^{-3}, \quad \mathbf{\square 0 0} \mathrm{mol} \mathrm{m}^{-3}$

SDS solutions

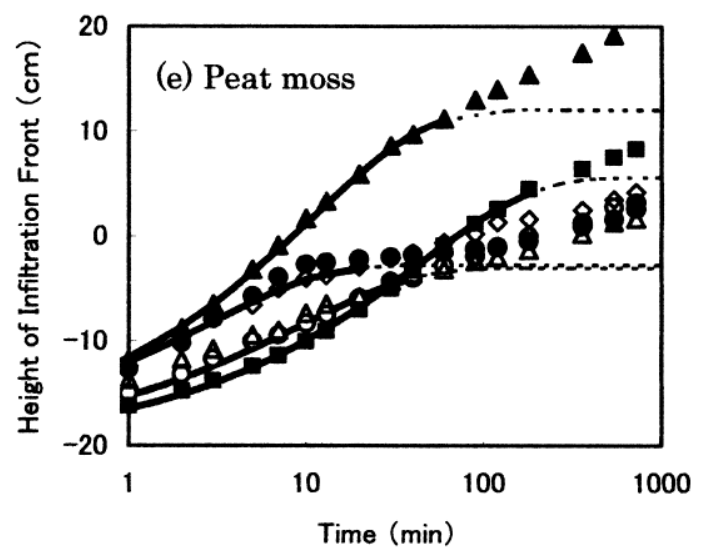

Fig. 2 Height of infiltration front during upward infiltration of SDS (sodium dodecyl sulfate) solution. Symbols are measured values. Solid lines are calculated values fitted with measured data. Dotted lines are calculated values that follow solid lines. The lines are fitted with the measured values for $0 \mathrm{~mol} \mathrm{~m}{ }^{-3}, 7 \mathrm{~mol} \mathrm{~m}^{-3}, 70 \mathrm{~mol} \mathrm{~m}^{-3}$ and $700 \mathrm{~mol} \mathrm{~m}^{-3}$ SDS solutions. 


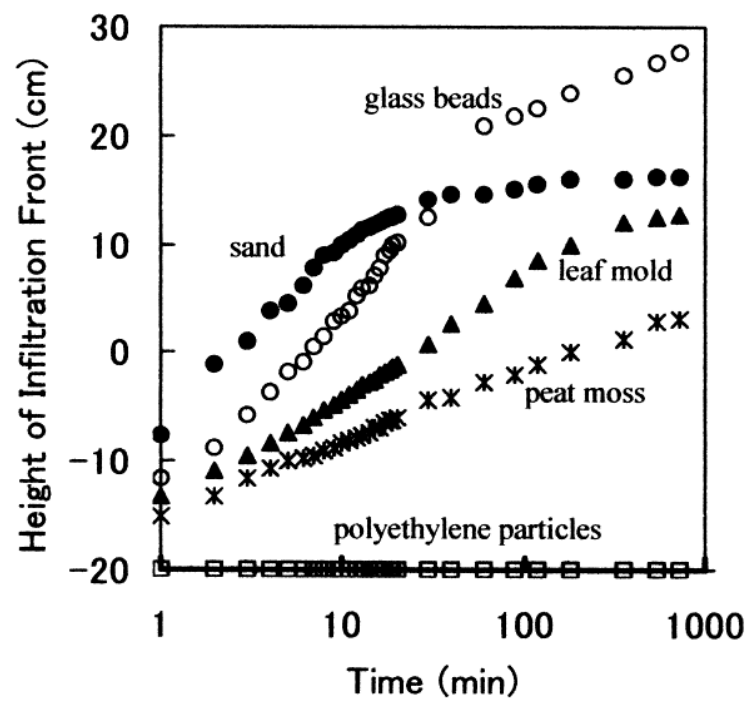

Fig. 3. Height of infiltration front during pure water infiltration. 


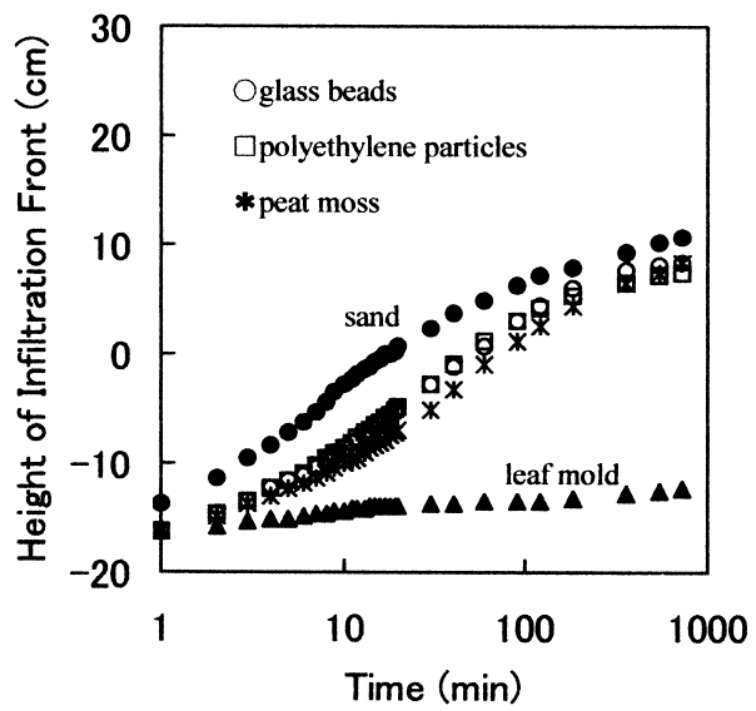

Fig. 4. Height of infiltration front during $700 \mathrm{~mol} \mathrm{~m}^{-3}$ SDS solution infiltration. 


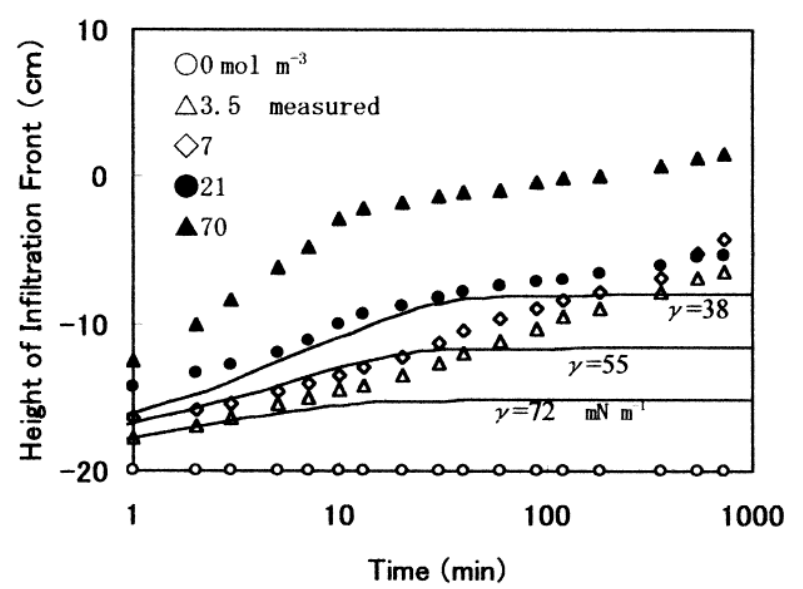

Fig. 5. Height of infiltration front in the polyethylene particles column. Solid lines are the calculated curves with different surface tensions and the same advancing contact angle $\left(\theta=110^{\circ}\right)$. 


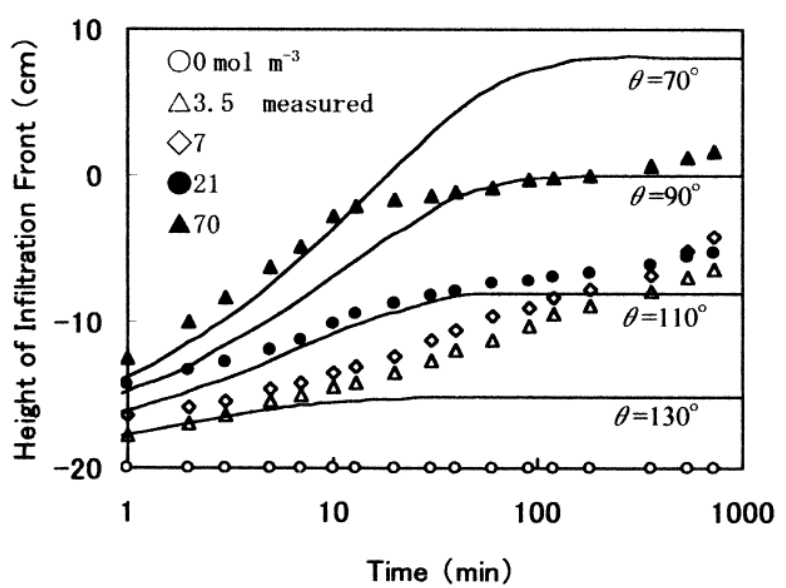

F ig. 6. Height of infiltration front in the polyethylene particles column. Solid lines are the calculated curves with different advancing contact angles and the same surface tension $\left(\gamma=38 \mathrm{mN} \mathrm{m}^{-1}\right)$. 